\title{
J
}

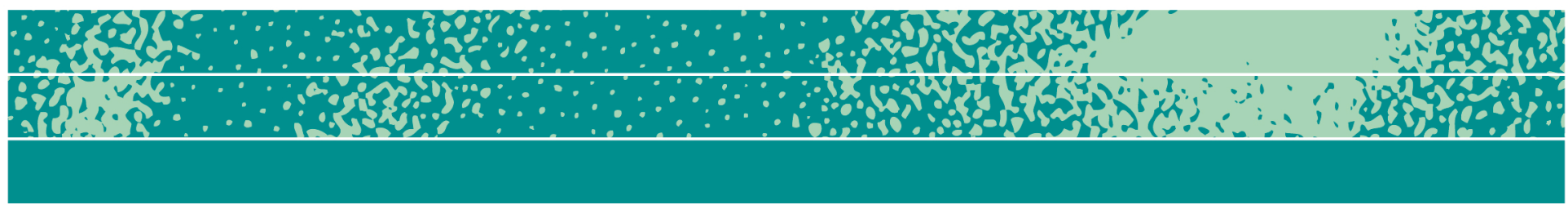

\section{Teach Your Children Well: (How and) Why Design Anthropology Speaks to Our Students}

\author{
Lisa DiCarlo
}

\begin{abstract}
This paper explores design anthropology as a topic of study among university students. After establishing a working definition of design anthropology, I will use a case study from class to illustrate several aspects of the discipline that appeal to students: holism in research, understanding before action, and stakeholder engagement. I conclude with a discussion of the importance of informed intervention as an appealing outcome for students.
\end{abstract}

Keywords: Teaching, design anthropology

\section{Chance Encounters in the Field: Anthropology's Best-Kept Secret}

While working on a national study of the entrepreneur's experience in the US in 2011, I found myself for the first time on a team of researchers from graphic design, industrial design, architecture, and user experience. Our task was to understand the entrepreneur's experience in context with the aim of informed intervention in entrepreneurship education. From our earliest meeting, it was clear that each team member represented a distinct discipline-bound language and set of assumptions about
Page 1 of 11

JBA 7(2): 268-278

Autumn 2018

(C) The Author(s) 2018 ISSN 2245-4217

www.cbs.dk/jba 
hierarchy and protocol. We needed to create a way to communicate above and beyond these disciplinary constraints. One of the team members recommended Creating Breakthrough Ideas (Squires and Byrne 2002) for the project's reading list. This chance introduction to design anthropology, while timely and helpful for the project at hand, was also disturbing in the respect that I was hearing about it for the first time relatively late in my career. Undergraduates and graduate students alike were getting degrees in anthropology without having learned about all of its possible applications. To that end, I developed the design anthropology course described below for college students. It has been both gratifying to introduce students to this aspect of our discipline and frustrating to find so few resources toward which to guide them. Even as of this writing, a search for design anthropology expertise in academia on the AAA website's AnthroGuide yields a listing of two academic institutions in the U.S. Not only are we keeping this sub-discipline a secret from our students, we are also keeping it a secret from ourselves.
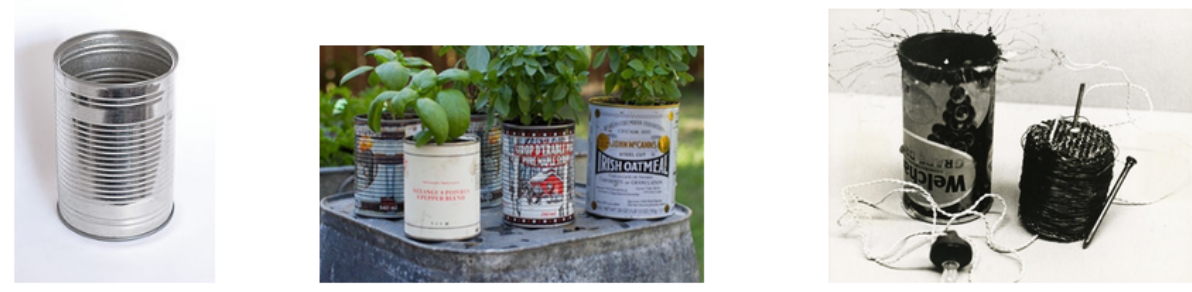

Figure 1. A mass-produced ('made') tin can; everyday use of a tin can ('found'); Victor Papanek's tin can radio, made from locally found materials in Indonesia (1971).

\section{Design Anthropology Defined}

Otto and Smith (2013) describe design anthropology as a distinct style of knowing that challenges anthropology's traditional contribution of theoretical analysis and demands practical implications, predictions and alternative ways of proceeding forward into the future. Indeed, Crouch and Pearce (2013) describe a design anthropology that joins the creative yet isolated labs and studios of design with the documentarist of 'real' worlds. In addition to the ethnographic methods of the documentarist, Clarke (2018) points out the critical importance of anthropology's theoretical emphases to the service of design. Anthropology is not simply the camera; it is the filter that gives depth and texture to what is viewed through the design lens. Theory becomes generative as opposed to contemplative. Insights from ethnographic fieldwork, aside from promoting a critical understanding of the object of study, are incorporated into the process of designing according to context. Anthropology keeps design in check, and design keeps anthropology 
engaged with the context it explains. Both design and anthropology continue to contend with their respective colonialist legacies. Positioning these practices face-to-face keeps anthropology and design relevant to and representative of their communities of engagement in the most beneficial way.

\section{Answering the 'So what?' Question}

By now, everyone is familiar with the concept of the academic silo. Disciplines and departments can operate as independent entities and are not incentivized to collaborate across those lines (Di Carlo et al. 2014). Courses co-taught by faculty from different disciplines are still rare birds. The number of interdisciplinary journals is still dwarfed by journals with a singular focus on one way of knowing. Extending the liberal arts education from a particular way of knowing to a collaborative way of doing is not only not required; it is often frowned upon (Colletta 2010). The idea that students will have the greatest impact if they succeed in developing a critical understanding of the complexity of the human experience is a popular one - and one that feeds nicely into the postmodernist hangover ${ }^{1}$ that resigns us to inaction and belief in the imprudence of application.

If we are not educating our students to bring their critical thinking skills and nuanced Weltanschauung to bear on making the world a better place, then what is our contribution to the world off campus? Yes, it's complicated. Yes, it's all connected. So what?

Context Research for Innovation is a course I offer in alternating years at Brown University. As an anthropologist housed in a Sociology Department, I was not at liberty to use the term 'design anthropology' in the title when I created it years ago. I can now see that it was advantageous to eschew the language of academic turf wars. Students from engineering, anthropology, industrial design, and business regularly sign up for the class.

Design anthropology by any name appeals to university students in liberal arts colleges and business schools alike. ${ }^{2}$ In the pages that follow, I will explain how I introduce students to the concept and why it appeals to them. I will end with a discussion of design anthropology as our discipline's best path forward.

\footnotetext{
${ }^{1}$ Sigridur Duna Kristmundsdottir. 1999. “'Father did not answer that question': power, gender and globalization in Europe." In The Anthropology of Power. Angela Cheater, Ed. Oxford: Routledge. Pp. 42-56.

${ }^{2}$ The author taught a similar course at Babson College before joining the faculty at Brown University.
} 


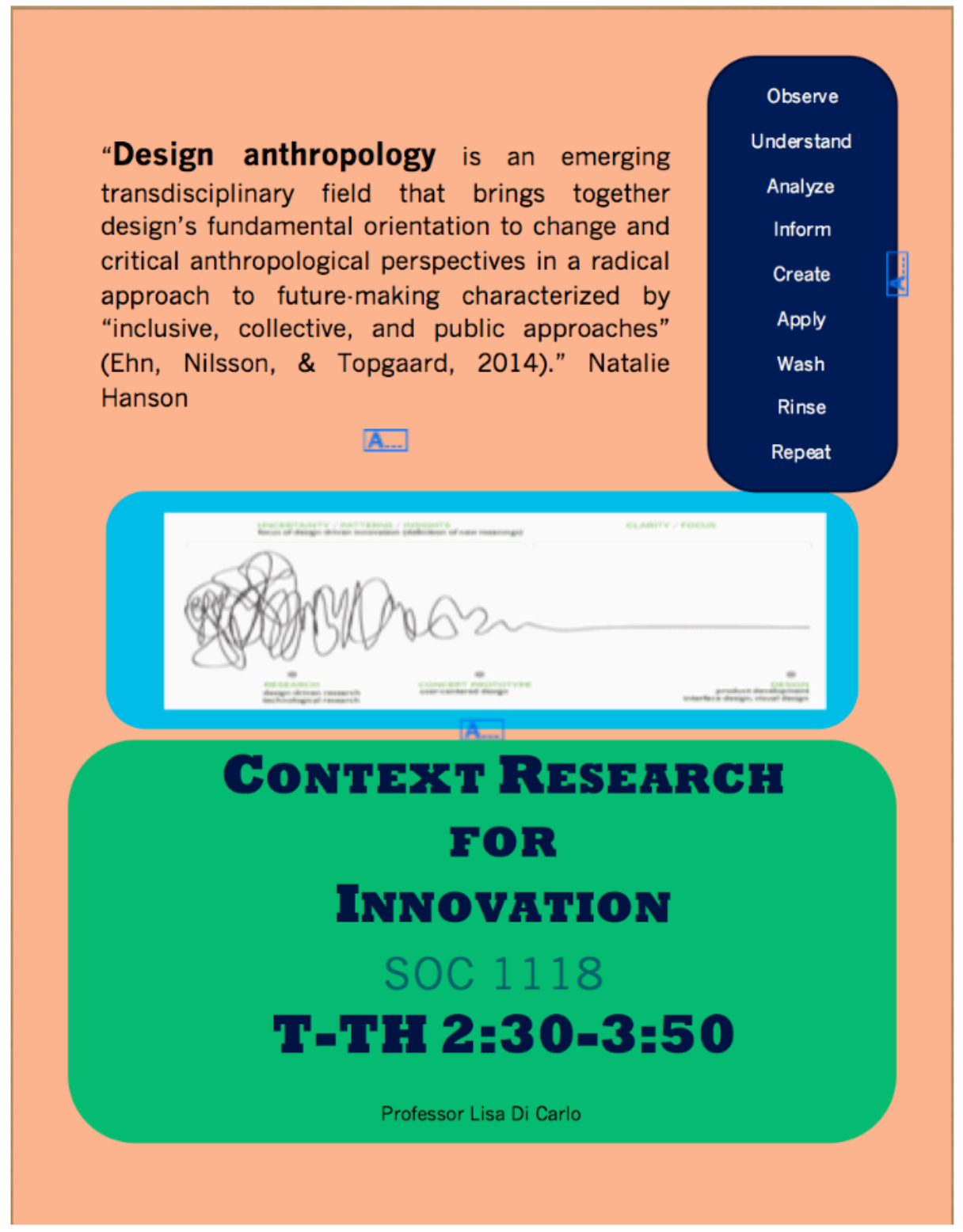

\section{Design Anthropology's Appeal at the University}

A cursory look at Brown University's course offerings reveals titles such as "So You Want to Change the World" and "Anthropology and Global Social Problems" from the Anthropology department, and "Appropriate Technology", and "Why Changing the World is Difficult" from the Engineering department. Biology is the most popular area of study at Brown today. Entrepreneurship is in the top 5, and Engineering follows closely behind. Our closest neighboring institution is Rhode Island School of Design (RISD). Brown and RISD students enjoy reciprocal course enrollment privileges. There are informal arrangements between some Brown and RISD faculty members who try to collaborate across disciplines such as industrial design, engineering, entrepreneurship and social sciences. It is not surprising that the students involved in such collaborations would create a conference, now 10 years in the running, which explores this particular intersection of perspectives. Better World 
by Design (locally known as BWxD) is now an annual conference of international scale. Speakers are typically social entrepreneurs, innovators, engineers, and returning alumni who have launched design ideas with social impact. Participants can listen to talks, take part in workshops run by design consultancies, entrepreneurs and professors, and network with potential mentors. The conference sells out shortly after tickets go on sale.

Despite all hope to the contrary, BWxD often draws from the crowd outside of Providence for the majority of its participants. As a professor, I would like to see all of my students attend (and if admission were free I would require it). The barrier to attendance turns out to be the actual name of the conference: A Better World by Design. We have trained our students to dismiss activities that don't speak to their strengths, or at least do not do so in a transparent way. Design is still an opaque term that belongs at RISD, that other school down the hill. Even at RISD, students of photography, metalsmithing and sculpture dismiss the conference as irrelevant to their pursuits.

For those of us interested in anthropology's contribution to the field of design, the conference is peppered with cautionary tails about uninformed assumptions, hasty design, and trips back to the proverbial drawing board. It was at this conference that I gave my first workshop in anthropological field methods for designers, in 2011. Context Research emerged shortly thereafter. Note the absence of the word 'design' in the title.

Students enroll in Context Research without really knowing what it is. They are often familiar with its discrete components rather than the sum of its parts. They know that it counts as a research methods course, that the professor is an anthropologist, and that there will be a connection with design. I have created a flier that conveys a course that is active, creative, interdisciplinary, and generative of solutions. This is in contrast to courses that frequently allow students to explore problems and crises, often brought on by the very people that seek to solve them. This is an important topic of exploration. However, when courses end where they started, students leave with no sense of how to move in the direction of solution-oriented change.

In Context Research, students spend 13 weeks on interdisciplinary teams, working to understand the context of a particular problem that they hope to solve. During that time, they experiment with field methods to understand which method yields which kind of data, how methods are best sequenced, how long a given method might take to execute, and how three team members asking the same question can hear three different answers. Students are given a chance to prototype solutions at the very end of the semester. The end product is not a prototype but a research proposal, written in response to an RFP. They 
come away from the course understanding how to approach projects with a methodological sequence that is contextually informed, theoretically grounded, and solution-oriented. They learn from guest speakers in the field about the difference between academic research and research in an industry or other applied context. And they learn something about communicating across disciplines after working on teams that have been intentionally designed to include students from engineering, design, social science and humanities.

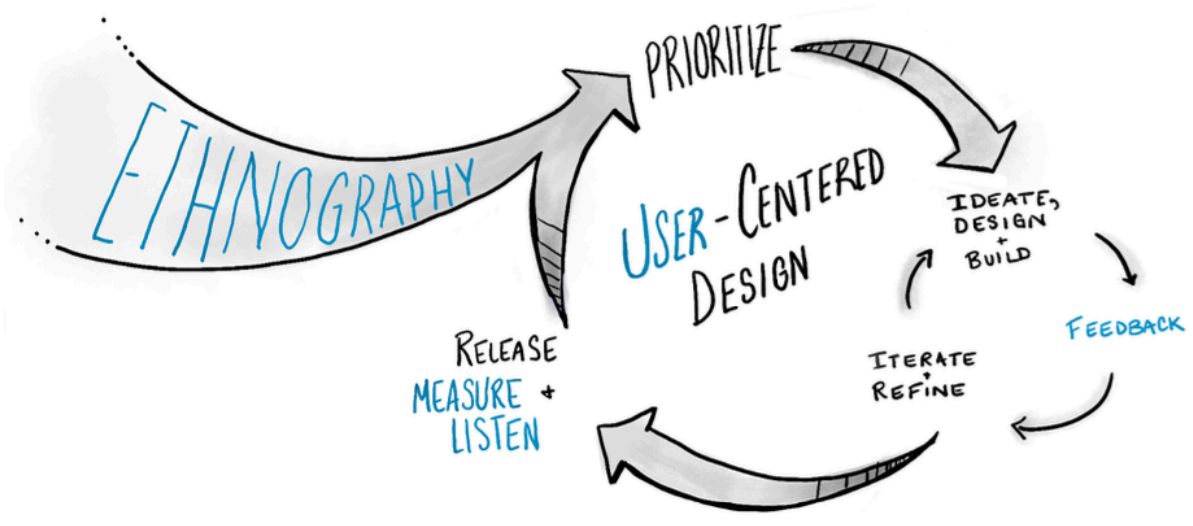

Figure 2. The role of the ethnographer at Photoshop. www.designthatmatters.org

\section{From NeoNurture to Firefly ${ }^{\mathrm{TM}}$ : A Case Study}

Design That Matters (DtM) is a non-profit organization based in Salem, Massachusetts. It describes itself as an organization that solves problems for and with the poor in developing countries. In a TED talk from 2012, Timothy Prestero, CEO of Design That Matters, explains his organization's journey from designing for inspiration to designing for outcomes. The eventual creation of Firefly, a user-friendly phototherapy device, started with the invention of NeoNurture, an incubator for hospitalized newborns in developing countries. An examination of DtM's emerging design process serves as a good case study to highlight the importance of the perspectives and practices of design anthropology.

In order to allow students to apply the principles of design anthropology to the case as it unfolds, I require them to commit to engaging with the relevant materials at a dictated pace. They explore the organization's website as well as some background reading material in addition to the first three minutes and forty two seconds of the TED talk. The combined materials ("Part I") introduce them to the following situation: 


\section{The Problem:}

According to Prestero, 4 million babies around the world die before their first birthday. 1.8 million would survive if they could be kept warm for the first three to seven days of life. In developing countries such as Nepal, hospitals typically use blankets to keep newborns warm. Although hospitals in developed countries may donate old incubators to developing countries as they upgrade to new equipment, such donations are only useful in the short-term, or until the equipment breaks down and requires unavailable technicians and spare parts.

\section{The Challenge:}

How can we keep hospitalized newborns warm through the first week of life?

\section{Considerations:}

- Technology must be locally sourced so it can be locally repaired or replaced.

- Any devices created must be user-friendly.

- Affordability is a priority.

\section{Strategy:}

Create a concept that will inspire manufacturers and other people of influence to "take the design and run with it" (Prestero 2012).

\section{Field Research:}

According to Prestero, his team spent months conducting user research, incorporating perspectives from doctors, nurses, repair technicians, and parents. They created multiple prototypes and incorporated feedback from user-end stakeholders to develop their final concept.

\section{Outcome:}

The NeoNurture was created and lauded as a breakthrough innovation in Time magazine's "50 Best Innovations of 2010" issue. According to Prestero, the only time a child was ever placed in the NeoNurture was during the Time magazine photo shoot. What should have been an example of breakthrough innovation turned out to be a failure. 


\section{Context Research Intervention}

After sharing Part I of DtM's case, the class has to try to figure out what went wrong. They map out a model of stakeholder engagement that includes all parties mentioned in the material included in Part I. It usually looks something like this:

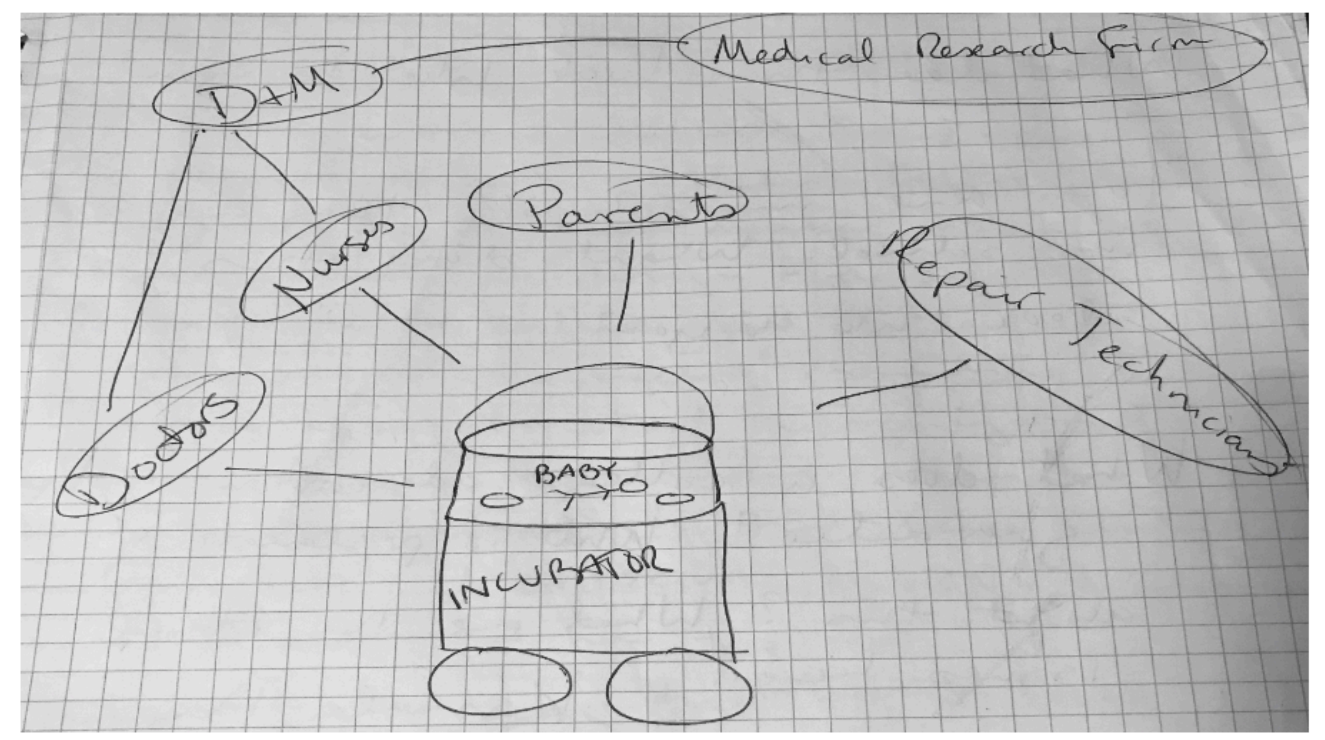

Indeed, this is a good rendering of the user-end of stakeholder engagement. These are the stakeholders Prestero mentions as the focus of his team's countless hours in the field. But what about product design, creation, and delivery?

\section{What Happened?}

Prestero's explanation of NeoNurture's failure is revealing. His team had designed a product with the intention of inspiring manufacturers and people of influence to take the next steps. His team later realized that designing for outcomes means also considering the sources of manufacturing and distribution. While the research team had spent considerable time studying users, they had not taken into consideration what motivates manufacturers and distributors. In the end, they learned that when the customer isn't the buyer, it is also important to consult the buyer. In the case of the Bangladeshi hospital director shown in Prestero's talk, the local Ministry of Health decides which products to purchase for the hospital. Similarly, manufacturers in emerging markets produce goods that will sell to local buyers. Johnson and Johnson in Bangladesh manufactures - and sells - products aimed at the middle class, whose health issues focus more on heart disease and infertility than hypothermia in hospitalized newborns. Ultimately, NeoNurture turned out to be a design that was neither grounded in outcomes nor inspirational - beyond the pages of Time magazine. 
Below is the revised illustration of stakeholder engagement. It takes into account the elements of context that came into focus in hindsight:

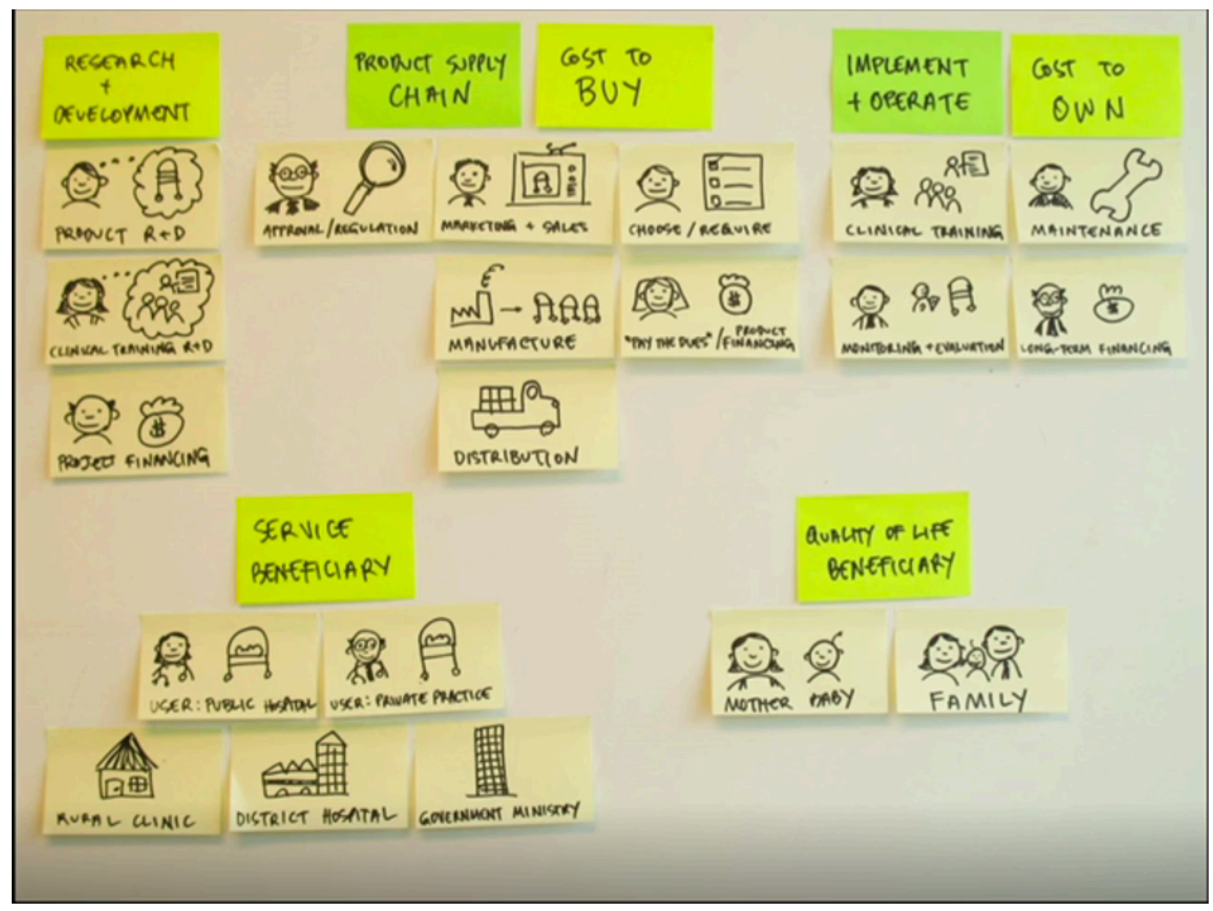

Figure 3. Frame from Tim Prestero's TED talk explaining a more complex context for design than the user-focused context his team initially assumed.

With this new understanding of context, which only came about as a result of the failure of NeoNurture, Prestero's team incorporated the principle of Design for Manufacture and Distribution into their goal of designing for outcomes.

\section{Part II of the Design That Matters case: The Creation of Firefly ${ }^{T M}$ and a} Design Manifesto

Prestero's team pivots to work on creating a product that will help children with jaundice. Instead of starting at the user end, the team spends months on the ground with manufacturers to learn what was possible and desirable to produce, as well as with distributors to learn how products are distributed and purchased. With a firm understanding of the production context, they proceeded to work with medical teams to develop a feasible phototherapy device for infants. This involved developing an understanding of the intersection of intended and actual use of medical equipment. In Prestero's words, there is no such thing as a dumb user. There are only dumb designs. If nurses are placing more than one baby in a phototherapy device, thereby depriving both (or all three) babies of the recommended amount of blue light, it is indicative of poor design and, perhaps, a shortage of devices. Understanding actual use is a 
crucial step in designing for successful use. In this case, the device was built so that it could only physically accommodate one child. If mothers are putting blankets over their babies to keep them warm and this ends up blocking the blue light, as was happening with the actual use of the machine, then DtM needed to treat it as a design challenge. The device was built with light coming in from above and from below so mothers could take care of their children without impeding phototherapy.

Designing for outcomes is only possible when actual use is taken into full consideration.

Finally, Prestero's team learned that designing for appearance is an important component of designing for outcomes. Field workers reported seeing many perfectly good pieces of medical equipment that weren't purchased or used because of their appearance. In Prestero's words, ER reruns have conditioned everyone to expect 'Buck Rogers'. If the equipment works, but the design is not aesthetically appealing to the target market, the product will fail.

\section{Designing for Outcomes and Design Anthropology}

By the time we finish with Part II of the DtM case, students in the class understand how anthropology can inform design and how design can mobilize a practice of anthropology. In fact, the mobilization is reciprocal. It was the anthropological practice of understanding local context, meanings and systems of production that brought DtM forward from an inspirational concept car (NeoNurture) to a product with the ability to solve a problem. Designing for outcomes requires understanding the entirety of the product's context, from cradle to grave. It requires understanding how products are used regardless of the intended use. It also requires understanding local constructions of aesthetic value regardless of the product's function. These are all points of intervention that students discover, work through, and learn how to assess in Context Research for Innovation.

With complementary goals of holistic understanding and contextappropriate solutions, design anthropology offers students a chance to learn how to participate in creating the future. This prospect is particularly enticing for students of engineering, business, public health, development studies, and other disciplines that offer opportunities for creating products, designing systems, developing services and enhancing experiences. 


\section{References}

A Better World by Design. http://betterworldxdesign.com/index.html.

Clarke, Alison J., ed. (2018). Design Anthropology: Object Cultures in Transition. New York: Bloomsbury.

Colletta, Lisa. (2010). "The Ultimate Utility of Nonutility." Academe. September-October 2010. Retrieved from https://www.aaup.org/article/ultimate-utility-nonutility\#.

Crouch, Christopher, and Jane Pearce. (2013). Doing Research in Design. Oxford: Berg.

Di Carlo, L., H. McGowan and S. Rottenberg et al. (2014). "Anthropology in a Design, Engineering and Commerce Curriculum" in Handbook of Anthropology in Business, 247-265. New York: Routledge.

Gunn, Wendy, T. Otto and R.C. Smith. (2013). Design Anthropology Theory and Practice. New York: Bloomsbury.

Hanson, Natalie. (2016). Design Anthropology: Discovery and Evidence of Emerging Pathways in Anthropology. Retrieved from https://nataliehanson.com/2016/11/18/aaa16-design-anthro/. Papanek, Victor. (1971). Design for the Real World: Human Ecology and Social Change. New York: Pantheon Books.

Pearson, Charles. (2015). "What Does an Ethnographer Do?" (Diagram) Retrieved from https://medium.com/startup-study-group/my-twoyears-as-an- anthropologist-on-the-photoshop-team-e700acb7d3 d5.

Prestero, T. (2012). Timothy Prestero: Design for people, not awards. [Video file.] Retrieved from https://www.ted.com/talks/timothy prestero design for people not aw ards.

Squires, Susan and B. Byrne, eds. (2002). Creating Breakthrough Ideas: Anthropologists and Designers in the Product Development Industry. Bergin and Garvey.

Suchman, Lucy. (2011). "Anthropological Limitations and the Relocation of Design.” Annual Review of Anthropology 40: 1-18.

https://doi.org/10.1146/annurev.anthro.041608.105640

Lisa Di Carlo is an anthropologist and lecturer at Brown University. She teaches courses in design anthropology, ethical entrepreneurship, and ethnographic methods in industry. A Mediterranean specialist by training, Dr. Di Carlo conducts most of her fieldwork in Turkey and Turkish diaspora communities. She focuses on innovation and social change, migration, and identity politics. Dr. Di Carlo is a Fulbright-Hays senior scholar and the author of Migrating to America: Transnational Social Networks and Regional Identity among Turkish Migrants. 